\title{
The Doctor's New Clothes: Professional or Fashionable?
}

Chantal Hartmans ${ }^{1}$, Stefanie Heremans ${ }^{1}$, Marieke Lagrain ${ }^{1}$, Kristin Van Asch ${ }^{1}$ and Birgitte Schoenmakers ${ }^{2 *}$

${ }^{1}$ Department of Public Health and Primary Care Academic Centre of General Practice, University of Leuven, Leuven, Belgium

${ }^{2}$ Academic Teaching Practice, Department of Public Health Academic Centre of General Practice, Leuven, Belgium

\begin{abstract}
Objective: To investigate the influence of the GP's attire on the confidence that patients have in their GP as a medical expert and on the patient's comfort level (defined as 'feel at ease').

Design: A cross-section study without control group.

Methods: Participants $(n=1506)$ completed a survey on the internet or in paper after seeing images of six models of three different age categories, each in five different clothing styles (leisure clothing, casual, semiformal, formal and professional). The following questions were asked for each model: "In which doctor do you have the most confidence as a medical expert?" and "With which doctor do you feel most at ease?".
\end{abstract}

Results: Patients trusted a female doctor and the older male doctor most when wearing professional clothing (white coat). The young and middle aged GP's were preferred to wear semiformal attire. Patients were most at ease with a female GP wearing leisure clothing. They preferred the young and middle aged male GP to wear semiformal attire, while patients were most at ease with the older male GP wearing casual clothing.

Conclusion: The GP's attire has an influence on the patient's confidence and comfort level. In general patients still mainly prefer a doctor in a professional outfit.

Keywords: General practitioner; confidence; wellbeing; clothing style; communication; medical sociology

\section{Introduction}

The clothing style of each professional has an important impact on presentation, credibility and appearance. Formal health care providers who are not wearing professional gear, have to guard and defend their professional attitude. General practitioners opted many years ago to abandon their white coats. Besides, a general practitioner is for many patients the counselor and trusted person par excellence. Patients expect a GP to prove scientific medical knowledge and skills, as well as to perform with a listening ear and moral support. Moreover, a good doctor-patient relationship is a basic requirement for good care provision. Without white coat, the way a GP dresses will have a significant influence on the development of the physician-patient relationship [1-3].

The clothing style is determined by tradition and fashion. For centuries, the white coat is seen as the symbol of the physician. Previous studies on the clothing style of doctors showed different results. Various studies have shown that a white coat is still preferred by many patients [4-6]. Others, one study revealed that the disappearance of medical paternalism has caused lower popularity of the white coat [7]. Particularly, in the case of pediatricians and psychiatrists, the white coat has lost its importance $[8,9]$. A study conducted in New Zealand demonstrated that patients prefer a semi formal outfit for their treating medical doctor [7]. All the above mentioned studies have been carried out in a specialist setting. Little research has been done on the clothing style of GP's. A single study from the Netherlands showed that formal attire generates more confidence in patients. The white coat, however, was omitted here [10].

The major research question of this study was: do the clothes make the family doctor? This study examined whether the attire of the GP affects the confidence and the 'feel at ease' of patients

\section{Methods}

\section{Research questions and outcome}

In this study, two issues were examined:
- Has the clothing of GPs an effect on the confidence that patients have in a GP?

- Do patients feel more at ease with a certain clothing style of the GP?

The outcome measures were defined as the confidence of the patient in the doctor as a medical expert and the patients' feeling 'at ease' with the doctor.

The following questions were formulated for each model: "In which doctor/clothing style do you have the most confidence on the level of medical affairs?" and "Which doctor/clothing style makes you feel most at ease?". The participants were asked to make a single preference. Finally, socio-demographic information was requested: age, sex, occupation, highest educational level and whether the participant has a regular GP. Participants completed the survey independently, without interview, to avoid any interference and to guarantee anonymity.

\section{Study Population}

A questionnaire was developed based upon earlier research and with additional items. This questionnaire was distributed from 1104-2013 until 28-05-2013 through social media (Facebook, Senioren $\mathrm{Net}$ ) and e-mail. In addition, from 15-04-2013 until 17-05-2013 paper versions of the survey were deposited in the waiting rooms of medical polyclinics and of five representatives (certified as regional

*Corresponding author: Schoenmakers B, Department of Public Health Academic Centre of General Practice, University of Leuven, Kapucijnenvoer 33, block J, box 7001, Leuven, Belgium, Tel: +32495235639; E-mail: Birgitte.schoenmakers@med.kuleuven.be

Received November 25, 2013; Accepted December 30, 2013; Published January 07, 2014

Citation: Hartmans C, Heremans S, Lagrain M, Asch KV, Schoenmakers B (2014) The Doctor's New Clothes: Professional or Fashionable? Primary Health Care 3 145. doi:10.4172/2167-1079.1000145

Copyright: (c 2014 Hartmans C, et al. This is an open-access article distributed under the terms of the Creative Commons Attribution License, which permits unrestricted use, distribution, and reproduction in any medium, provided the original author and source are credited. 
reference and academic teaching practices) group practices of general practitioners. The questionnaire could be completed by anyone aged 18 or more. Since in Belgium all citizens are equally insured by the national social security system, all medical houses and polyclinics are accessible to all patients.

\section{Design}

The study was performed in a cross-section without control group. The survey showed six doctor-models presenting with five different clothing styles. Images were taken against a neutral background and models were presented in the same position, with a similar facial expression by a professional photographer. The six models represented each a different category of general practitioners: the very young female doctor (25-35 years), the female doctor (35-50 years), the older female doctor ( $>50$ years), the very young male doctor (25-35), the male doctor (35-50 years) and older male doctor ( $>50$ years).

The five clothing styles were defined as follows:

- Leisure Clothing: for men a T-shirt, jeans and sneakers, for women T-shirt, jeans and ballet flats, boots or sneakers.

- Casual: for men casual shirt or sweater dressed with shirt underneath, a casual pants or dark jeans and sporting dressier shoes, for women T-shirt, skirt or dressy pants and flats or boots.

- Semi-formal: for men a shirt with possibly a sporty jacket, pants and dress shoes, for women blouse, skirt with tights or possibly a smart pants and shoes with a small heel.

- Formally: for the men dressed with a shirt jacket, trousers and dress shoes, the women a smart dress with a blazer or a suit.

- Professional: aforementioned semi-formal outfit with white coat.

- All models were asked to choose the outfits from their own clothing collection. If necessary, the authors revised the personal clothing choice to guarantee a representative and conform look (Appendix 1).

The images were printed in color, format A4, sorted by model and bundled in the above mentioned and fix sequence for the paper questionnaire. The online questionnaireshowedfor each model the five images next to each other, in the same order as listed above.

\section{Statistical analysis}

A univariate analysis was used to in answer to the primary research question and to describe the socio-demographic features of the participants. Furthermore, a multivariate analysis was applied by a logistic regression in SAS 9.3, with the independent variables being gender, age and education and dependent variables being confidence in the doctor in the medical field and to feel at ease with the doctor. Odds ratios with $95 \%$ confidence intervals were described for each dependent variable in relation to the subsequent independent variables.

\section{Ethical approval}

The Medical Ethics Committee of K.U. Leuven University Hospital approved the study as part of the Master Thesis to achieve the title of Master in Medicine. A written informed consent of the study participants is in Belgium only required when medical data on patients are involved.

\section{Results}

\section{Study population}

The total group consisted of 1506 patients. 1324 of them have completed the entire questionnaire. The data of the incomplete questionnaires were handled as 'missings' (computation of missings in SAS 9.3).

The average age of the patients was 38.35 years and $68.29 \%$ of the participants were female $(\mathrm{n}=911)$. With regard to education, the majority of participants were highly skilled: $32.46 \%$ had a higher education diploma $(n=436)$ and $38.64 \%$ obtained a university degree $(n=519)$.

Of all participants $27.58 \%$ were employees, $26.02 \%$ students, $13.53 \%$ officials, 7,14\% independent professionals, $4.83 \%$ laborer and $20.90 \%$ housewife or -man, unemployed, disabled, retired or otherwise.

$91,14 \%(n=1224)$ of all participants group had a regular general practitioner (Table 1).

\section{Confidence in the doctor as medical expert (appendix 2)}

The study found that patients have the most confidence in a female doctor wearing a white coat. As regards model $1,49.56 \%(n=730)$ chose the professional outfit, in our second model $51.52 \%(\mathrm{n}=745)$ and in model 3 amounted this $44.22 \%(n=631)$. The age of the female doctor did not affect this preference (Appendix figure 1). The remaining sequence differed in function of the age of the female doctor. It appeared that patients chose as second option the formal clothing in the young female doctor $(26.14 \%, \mathrm{n}=385)$. As third choice the leisure outfit was chosen $(9.98 \%, \mathrm{n}=147)$, followed by the casual $(7.47 \%, \mathrm{n}=110)$ and semi-formal clothing $(6.68 \%, \mathrm{n}=101)$. Regarding the middle-aged female doctor, patients secondly selected the leisure outfit $(17.57 \%, \mathrm{n}=254)$, followed by the semi-formal attire $(14.04 \%, n=203)$, casual wear $(9.75 \%, n=141)$ and formal clothes $(7.12 \%, \mathrm{n}=103)$.

Concerning the elderly female general practitioner finally, leisure clothes were most trust worthy, after the professional outfit $(23.06 \%$, $\mathrm{n}=329)$. These choices were followed by the semi-formal attire $(18.50 \%$, $\mathrm{n}=264)$, the formal attire $(10.79 \%, \mathrm{n}=154)$ and casual clothing $(3.43 \%$, $\mathrm{n}=49$ ).

As regards the male doctor, there was in terms of confidence rather a preference for semi formal attire: in both the younger doctor $(43.41 \%$, $\mathrm{n}=606)$, as the middle-aged doctor $(48.15 \%, \mathrm{n}=662)$, the majority of

\begin{tabular}{|l|c|}
\hline Feature & \% of total group \\
\hline Male & 31.75 \\
\hline Female & 68.29 \\
\hline $18-25 y$ & 34.59 \\
\hline $26-45 y$ & 31.12 \\
\hline $46-65 y$ & 28.93 \\
\hline$>65 y$ & 5.36 \\
\hline Diploma elementary or secondary school & 28.89 \\
\hline Diploma graduate school or university & 71.10 \\
\hline Employee & 27.58 \\
\hline Student & 26.02 \\
\hline Official & 13.53 \\
\hline Independent & 7.14 \\
\hline Laborer & 4.83 \\
\hline Housewife, unemployed, retired, disabled or others & 20.9 \\
\hline Regular general practitioner & 91.14 \\
\hline
\end{tabular}

Table 1: Socio-demographic data of participants group. 
patients chose semi-formal clothing as most confident outfit. The professional clothing endedona second place in both models (model $432.16 \% \mathrm{n}=449$; Model $527.56 \% \mathrm{n}=379$ ). Regarding the older male doctor, the patients chose the white coat $(38.11 \%, n=519)$ as most confident outfit, but the casual clothing was a good second choice $(38.03 \%, \mathrm{n}=518)$ (Appendix figure 2). The semi formal attire followed in third place $(16.01 \%, \mathrm{n}=218)$.

\section{Wellbeing: feeling at ease with the doctor (appendix 2)}

Patients were most at ease with a female doctor wearing leisure outfit, regardless of age (model $130.69 \% \mathrm{n}=452$; Model $231.33 \%$ $\mathrm{n}=453$; Model $348.49 \% \mathrm{n}=692$ ) (Appendix figure 3). For all three age groups the professional outfit was chosen as third option (model 1 20.23\% n=298; Model 2 23.65\% $n=342$; Model 3 18.22\% $n=260$ ).

In male general practitioners, there was again a distinction between the younger doctor and middle aged doctor, compared to the older male general practitioner. Patients indicated that they were most at ease with a young or middle aged general practitioner in semi formal attire (model 4 38.18\% $\mathrm{n}=533$; Model 5 41.31\% $\mathrm{n}=568$ ). In both cases, there was also an equal preference sequence: after semi-formal attire most patients opted for leisure clothing (model 4 26.93\% n=376; Model $526.47 \% \mathrm{n}=364$ ), followed by casual clothes (model 419 , 13\% with $\mathrm{n}=267$; model $517.24 \% \mathrm{n}=237$ ), professional clothing (model $412.32 \%$ $\mathrm{n}=172$; model $511.05 \% \mathrm{n}=152$ ) and formal attire (model $43.44 \%$ with $\mathrm{n}=48$, model 5 with $3.93 \% \mathrm{n}=54$ ).

Patients felt most at ease at a older male general practitioner, wearing casual clothes $(61.01 \%, \mathrm{n}=831)$ (Appendix figure 4$)$. This decision was followed by the white coat $(14.98 \%, n=204)$ and semiformal clothing $(14.24 \%, \mathrm{n}=194)$. Leisure clothing was now chosen as a last option $(4.7 \%, \mathrm{n}=64)$ (Table 2$)$.

\section{Factors influencing the preference of the participants}

The analysis showed that a number of socio-demographic data had an impact on the choices patients made. Regarding the outcome 'confidence' participants with a diploma of higher secondary education less often chose professional clothing, compared with participants who had a university degree (odds ratios: model 10,670 ; Model 2 0.735; model 5 0.729; model 6 0.636). Age also appeared to be important: participants between 18 and 25 years chose less often a white coat when it came to confidence than participants being older than 65 years (odds ratios: 0.602 Model 1, Model 3 0.703, 0.587 Model 5). The other features did not significantly influence the preference of the participants (Table $3)$.

Regarding the outcome 'feel at ease', there were also a number of socio-demographic data which were found to influence preference of the participants. In particular, the age played a major role in the preferences: for all six models participants between 18 and 25 years and 26-45 years chose more often a white coat to feel at ease, compared to participants older than 65 years (odds ratios: model 12,886 and 2,091, 3,377 and 2,666 model 2, model 32.344 and 2.565, 3.605 and 3.021 model 4, model 52.172 and 1.675, model 62.702 and 2.009). In model 2, 3 and 4, participants between 46 and 65 years chose more often a white coat compared to those over 65 years (odds ratios: 1.898 Model 2, Model 3 1.972, 1.919 Model 4). The results also showed that gender plays a role: men chose less often professional clothing to feel at ease than women (odds ratios: model 1 0,695; Model 2 0.689, 0.785 Model 3 , model 6 0.747). The other features did not significantly influence the preference of the participants (Table 4 ).

\begin{tabular}{|c|c|c|c|c|c|c|c|}
\hline & & Model 1 & Model 2 & Model 3 & Model 4 & Model 5 & Model6 \\
\hline & & \multicolumn{5}{|c|}{$\%$} & \\
\hline \multirow[t]{2}{*}{ Leisure } & Confidence & 9.98 & 9.75 & 23.06 & 5.80 & 7.05 & 0.95 \\
\hline & wellbeing & 30.69 & 31.33 & 48.49 & 26.93 & 26.47 & 4.70 \\
\hline \multirow[t]{2}{*}{ Casual } & Confidence & 7.47 & 17.57 & 3.43 & 13.68 & 7.49 & 38.03 \\
\hline & wellbeing & 19.35 & 27.66 & 8.27 & 19.13 & 17.24 & 61.01 \\
\hline \multirow[t]{2}{*}{ Semi-formal } & Confidence & 6.86 & 14.04 & 18.50 & 43.41 & 48.15 & 16.01 \\
\hline & wellbeing & 7.47 & 11.62 & 19.62 & 38.18 & 41.31 & 14.24 \\
\hline \multirow[t]{2}{*}{ Formal } & Confidence & 26.14 & 7.12 & 10.79 & 4.94 & 9.75 & 6.90 \\
\hline & wellbeing & 22.27 & 5.74 & 5.40 & 3.44 & 3.93 & 5.07 \\
\hline \multirow[t]{2}{*}{ Professional } & Confidence & 49.56 & 51.52 & 44.22 & 32.16 & 27.56 & 37.11 \\
\hline & wellbeing & 20.23 & 23.65 & 18.22 & 12.32 & 11.05 & 14.98 \\
\hline
\end{tabular}

Table 2: Percentage distribution by clothing for confidence and wellbeing.

\begin{tabular}{|c|c|c|c|c|c|c|}
\hline \multicolumn{7}{|l|}{ OR $(95 \% \mathrm{Cl}) \mathrm{P}$} \\
\hline Effect & Model 1 & Model 2 & Model 3 & Model 4 & Model 5 & Model 6 \\
\hline Male vs female & ns & ns & ns & ns & ns & ns \\
\hline Primary school vs university & ns & ns & ns & $0.3(0.1-0.7) p 0.08$ & ns & ns \\
\hline Lower second vs university & ns & ns & ns & ns & ns & ns \\
\hline Upper second vs university & $0.7(05-0.9) p 0.5$ & $0.7(0.6-0.9)$ p 0.4 & ns & ns & $0.7(0.6-0.9)$ p 0.9 & $0.6(0.5-0.8) p 0.7$ \\
\hline Graduate vs university & $0.7(0.6-0.9) p 0.9$ & ns & ns & ns & ns & ns \\
\hline $18-25 y$ vs $>65 y$ & $0.6(0.4-0.9) p 0.0009$ & ns & ns & ns & ns & ns \\
\hline $26-45 y$ vs $>65 y$ & ns & ns & ns & ns & $0.6(0.4-0.9) p 0.03$ & ns \\
\hline $46-65$ vs $>65 y$ & ns & ns & ns & ns & ns & ns \\
\hline
\end{tabular}

OR: odds ratio; $n s=$ OR not significant $(95 \% \mathrm{Cl}$ containing 1$) ; p=p$ value

Table 3: Odds ratio, $95 \%$ confidence interval and $p$-value, as regards confidence 


\begin{tabular}{|c|c|c|c|c|c|c|}
\hline \multicolumn{7}{|l|}{ OR (95\% Cl) P } \\
\hline Effect & Model 1 & Model 2 & Model 3 & Model 4 & Model 5 & Model 6 \\
\hline Male vs female & $0.7(0.6-0.9)$ p0.0008 & $0.7(0.5-0.8) p 0.0006$ & $0.8(0.6-0.9) p 0.08$ & ns & ns & $0.7(0.6-0.9) p 0.01$ \\
\hline Primary school vs university & ns & ns & ns & ns & ns & $0.4(0.1-0.9) p 0.05$ \\
\hline Lower second vs university & ns & ns & ns & ns & ns & ns \\
\hline Upper second vs university & $0.7(05-0.9) p 0.1$ & ns & ns & ns & ns & ns \\
\hline Graduate vs university & $0.7(0.6-0.9) p 0.9$ & ns & ns & ns & ns & ns \\
\hline $18-25 y$ vs $>65 y$ & $2.9(1.8-4.6) p<0.0001$ & $3.4(2.1-5.5) p<0.0001$ & $2.3(1.4-3.8) p 0.02$ & $3.6(2.2-5.9) p<0.0001$ & $1.1(0.8-1.4) p 0.3$ & $2.7(1.6-4.4) p<0.0001$ \\
\hline $26-45 y$ vs $>65 y$ & $2.1(1.3-3.3) p 0.02$ & $2.7(1.6-4.3) p 0.004$ & $2.6(1.6-4.1)$ p 0.0008 & $3.0(1.8-4.9) p 0.003$ & $1.7(1.03-2.7) p 0.2$ & $2.0(1.2-3.3) p 0.04$ \\
\hline $46-65$ vs $>65 y$ & ns & $1.9(1.2-3.1) p 0.5$ & $2.0(1.2-3.2) p 0.5$ & $1.9(1.2-3.1)$ p 0.3 & ns & ns \\
\hline
\end{tabular}

OR: odds ratio; $n s=$ OR not significant; $(95 \% \mathrm{Cl}$ containing 1$) ; p=p$ value

Table 4: Odds ratio, 95\% confidence interval and $p$-value, as regards wellbeing

\section{Discussion}

In this study, the impact of GP-clothing style on the confidence and on the 'feel at ease' of patients was observed. Results showed that there are clear differences between clothing styles regarding the 'feel at ease' of patients and the confidence they have in the medical expertise of their General Practitioner (GP). Here, the gender of the physician played a role. Patients had most confidence in a female GP when she wore a white coat, while the male young and middle-aged practitioner was trusted when presenting in semiformal attire. In case of the older male doctor, patients preferred the white coat.

On the 'feel at ease level of the patient, the gender of the GP determined the preferences. Leisure clothing is opted for the female doctor, while the semiformal outfit is preferred for the young and middle-aged male practitioner. Patients also preferred to see the older male doctor in casual attire (Table 2).

Regarding these results and in agreement with other research, the white coat still seemed to be the symbol of a trustworthy doctor $[2,3]$. Still, this was quite surprisingly, since it was stressed that each model represented a general practitioner and not a specialist. An explanation of this odd observation might be that in Belgium the specialist can also be consulted in a primary care setting. Specialists, considered as a higher echelon of care in the society, wear the white coat more often than GPs do $[3,11]$. This combination might mean that patients in Belgium are accustomed to the image of the white coat, relate this garment to a specialist and therefore grant more trust to the owner of it. The popularity of the white coat was also observed in other studies. The difference lied in the fact that these latter studies took place in a specialized setting [4]. Unlike these studies most participants in our study choose a non professional gear to feel at ease with a GP. It could be concluded that the white coat was experienced as an additional barrier in the doctor-patient-relationship in the GP setting.

There is a remarkable difference in the preferences made for the older male doctor, for both 'confidence' and 'feel at ease' in comparison with his younger and female colleagues. As with the female doctors, the white coat was opted when it comes to confidence in the medical expertise. This clothing was considered as more decent compared to the clothing of his younger colleagues (Table 2). A Dutch study also noted a difference regarding the older male doctor: casual clothing was little appreciated when worn by the older male doctor [10]. In this latter study there was no white coat included and only the 'confidence' of the patient was questioned. In this Dutch study a there appeared a major population bias: in one study group all participants were over 65 years, the other group only consisted of professionals in the healthcare sector. Finally, in our study less formal attire was chosen, when it comes to feel at ease with the doctor. A casual outfit is then preferred for the older male doctor.
Socio-demographic data affected the preferences of the participants. In the final analysis, profession was omitted as a variable, considering that it was too little discriminatory with the educational level. Similarly, the question "Do you have a regular GP?" was removed from the analysis, given nearly all participants had a regular family doctor. Regarding to confidence, older and higher educated patients prefer a white coatdoctor. The effect of age was also reported in a study in Britain where over-70s also opted significantly more the white coat [5]. This might be explained by a more traditional view on society and role patterns. The higher educated patient preferring white coats was a rather surprising observation. Perhaps these patients mirror themselves and their social and professional position to the doctor in front of them and expect him/ her toclearlyexceed them in expertise. Patients with al lower educational level might settle with 'doctor' as a trustworthy title and personality.

Regarding 'feel at ease', the age and gender of the participant affected the preferences for some models. Younger and female participants preferred a white coat to feel at ease with a doctor. Apparently, younger patients didn't want to 'friend' their doctor and preferred to keep a certain distance when it comes to personal interaction. Female patients also might, motivate by a more traditional background, feel more at ease when a doctor is dressed up professionally.

The effect of educational level seemed not a predictor of the patients' preference. A possible explanation was that health care in Belgium is affordable and open for all citizens. The threshold for visiting a doctor is therefore low for all socio-economic classes. All people felt at ease with their doctor regardless of his clothing style. An additional remark is that the low educated group in this study was rather under-represented, making it difficult to give a meaningful statement.

\section{Limitations and Recommendations}

This study also has some limitations. Some clothing styles resembled too much and a meaningful discrimination of preferences was therefore compromised. Leisure and casual attire were rather similar in both female and male doctors. Another weakness in the study is a possible sequence bias. However, the fixed order, as mentioned above, also provide a certain visual rest in the large amount of images.

In this study it was decided not to add the option "no preference". This could be a limitation but on the other hand it also allowed obtaining more significant results. Finally, this study was based on images and cannot be unconditionally translated to the daily practice. Moreover, the doctor-patient relationship (at long notice) is not only based on a first impression.

Strengths of the study are the large and representative study sample, the firm instructions given to the doctor models concerning the clothing style and the professional recordings. 
Citation: Hartmans C, Heremans S, Lagrain M, Asch KV, Schoenmakers B (2014) The Doctor's New Clothes: Professional or Fashionable? Primary Health Care 3: 145. doi:10.4172/2167-1079.1000145

As far as we know, this is also the first study in Belgium and worldwide that assessed the influence of clothing on the 'confidence' and 'feel at ease' with general practitioners. As already mentioned, a good doctor-patient relationship is essential. If clothing contributes to the confidence of the patient, it is definitely important to perform further research on this topic. For instance, does clothing style of their own GP influence the preference of the patients? Is the white coat more selected by patients who are often in a hospital setting? There are few studies on this subject so far. Given the effect shown in this study, further research is therefore recommended.

\section{Conclusion}

This study showed a clear influence of the GP's attire on the patient's confidence in the GP as a medical expert and on the patient's comfort level (feel at ease). Female doctors were expected to wear a white coat in order to be trusted while male doctors can afford a more relax clothing style. To feel at ease, patients preferred female doctors in leisure wear while male doctors were expected to be more dressed up. It seems that female doctors still have to 'earn 'patients' confidence while they are at the same 'this nice woman from next door' when patients are in need for a talk.

Finally, it is appropriate for a GP to pay attention to his/her attire, seen the influence of the clothing style on the doctor-patient relationship. Because of the effect found in this study and the limited amount of studies about this topic, further investigation is strongly recommended.

\section{References}

1. Gallagher J, Waldron Lynch F, Stack J, Barragry J (2008) Dress and address: patient preferences regarding doctor's style of dress and patient interaction. Ir Med J 101: 211-213.

2. McKinstry B, Wang JX (1991) Putting on the style: what patients think of the way their doctor dresses. Br J Gen Pract 41: 270, 275-278.

3. Neinstein LS, Stewart D, Gordon N (1985) Effect of physician dress style on patient-physician relationship. J Adolesc Health Care 6: 456-459.

4. Rehman SU, Nietert PJ, Cope DW, Kilpatrick AO (2005) What to wear today? Effect of doctor's attire on the trust and confidence of patients. Am J Med 118 1279-1286.

5. Douse J, Derrett-Smith E, Dheda K, Dilworth JP (2004) Should doctors wear white coats? Postgrad Med J 80: 284-286.

6. Sotgiu G, Nieddu P, Mameli L, Sorrentino E, Pirina P, et al. (2012) Evidence for preferences of Italian patients for physician attire. Patient Prefer Adherence 6: 361-367.

7. Lill MM, Wilkinson TJ (2005) Judging a book by its cover: descriptive survey of patients' preferences for doctors' appearance and mode of address. BMJ 331: 1524-1527.

8. Zwart DL, Kimpen JL (1997) [The white coat in pediatrics: link between medical history and preference for informally dressed physicians]. Ned Tijdschr Geneeskd 141: 2020-2024.

9. Nihalani ND, Kunwar A, Staller J, Lamberti JS (2006) How should psychiatrists dress?--a survey. Community Ment Health J 42: 291-302.

10. Kocks JW, Lisman-van Leeuwen Y, Berkelmans PG (2010) [Clothing make the doctor--patients have more confidence in a smartly dressed GP]. Ned Tijdschr Geneeskd 154: A2898.

11. Cha A, Hecht BR, Nelson K, Hopkins MP (2004) Resident physician attire: does it make a difference to our patients? Am J Obstet Gynecol 190: 1484-1488. 